\title{
Agenesis of right and existence of left inferior vena cava associated with posterior nutcracker syndrome
}

\author{
Serkan Burç Deşer, Semih Murat Yücel \\ Department of Cardiovascular Surgery, Medical Faculty, Ondokuz Mayis University, Samsun, Turkey
}

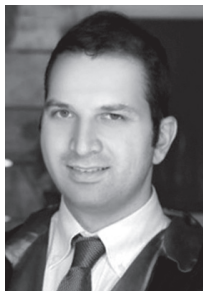

Kardiochirurgia i Torakochirurgia Polska 2017; 14 (4): 280-281

Congenital agenesis of the inferior vena cava is an uncommon congenital anomaly which can be misdiagnosed. Agenesis of the inferior vena cava has an incidence of $0.0005 \%$ to $1 \%$ in the general population [1]. The most common cause of agenesis of the inferior vena cava is the failure of embryological development between the sixth and the tenth weeks of gestation. Heterotaxy syndrome is associated with congenital cardiopathy, partial anomalous pulmonary venous connection, interruption of the inferior vena cava with azygos continuation, malalignment ventricular septal defect, multiple spleens, left superior vena cava, congenital pericardial defect, intestinal malrotation and pancreatic changes [2-4]. Blood flow through the collateral veins leads to an increase in the pressure of the leg veins, which causes chronic venous insufficiency and deep venous thrombosis. As a result, venous return is achieved through the lumbar azygos vein, hemiazygos vein, ascending lumbar veins, paravertebral veins, and anterior abdominal wall veins into the superior vena cava.

A 38-year-old woman diagnosed with agenesis of the inferior vena cava was admitted to us. On admission biochemical and physical examinations were normal. Computed tomography scan revealed partial agenesis of the anatomically normal right inferior vena cava above the renal veins, agenesis of right and existence of left inferior vena cava below the renal veins, associated with posterior renal nutcracker syndrome and enlargement of collateral circulation without any additional congenital cardiac, thorax and abdominal anomalies. The inferior vena cava interrupted below the right renal vein and venous blood flows directly into the left inferior vena cava; however, venous blood continues with the right inferior vena cava above the renal veins. The left renal vein courses posterior of the abdominal aorta and it was dilated due to the high flow and pressure, resulting in posterior nutcracker syndrome (Fig. $1 \mathrm{~A}-\mathrm{F}$ ). Due to the absence of complaints, we decided to follow up the patient with acetylsalicylic acid $100 \mathrm{mg} /$ day. The patient was doing well and did not show any symptoms after 6 months of follow-up.
Persistence of the left supra cardinal vein and regression of the right supracardinal vein lead to left inferior vena cava. Furthermore, the persistence of both supracardinal veins leads to double inferior vena cava. Agenesis of the inferior vena cava can be associated with polysplenia, dextrocardia, single ventricle or atrium, intestinal malrotation, pulmonary dysgenesis, renal agenesis, dextrocardia and cyanotic or a-cyanotic congenital heart diseases. Posterior nutcracker syndrome refers to the extrinsic compression of the left inferior vena cava that distorts the left renal vein flow [1]. It is usually detected incidentally, during surgery, angiography and computed tomography scans or autopsy. The most frequently observed symptoms are hematuria, left flank pain, abdominal pain, varicocele, abnormal menstruation, pelvic congestion syndrome, gonadal vein syndrome, orthostatic proteinuria and orthostatic abnormalities. Symptoms can be triggered or aggravated by physical activity, pregnancy or multiparity [5]. Left renal vein bypass, left renal vein transposition with polytetrafluoroethylene, Dacron or saphenous vein graft, medial nephropexy with excision of renal varicosities, superior mesenteric artery transposition, renal autotransplant, gonadocaval bypass and nephrectomy, wrapping of the left renal vein with ringed polytetrafluoroethylene are the surgical treatment options for posterior nutcracker syndrome [5]. However, current surgical therapy involves placement of an oversized renal vein stent with partial protrusion into the inferior vena cava to relieve stenosis and prevent stent migration. In the light of the current literature, we found only 4 cases of anomalies of the inferior vena cava presenting as nutcracker syndrome and to the best our knowledge this is the second case which consists of congenital partial agenesis of the inferior vena cava and left inferior vena cava associated with posterior nutcracker syndrome [2]. Anticoagulation/antiplatelet therapy is recommended, which would lower the risk of deep vein thrombosis and thromboembolic complications.

In conclusion, clinical follow-up of the patient without complaints is recommended for these circumstances; however, surgery may be indicated in a patient with the advanced

Address for correspondence: Serkan Burç Deşer, Department of Cardiovascular Surgery, Medical Faculty, Ondokuz Mayis University, 19 Mayis Üniversitesi, Tıp Fakültesi, Kalp ve Damar Cerrahisi Ana Bilim Dalı, Atakum, 55139 Samsun, Turkey, phone: +90 (362) 312 19 19/2615, fax: +90 (362) 45760 91, e-mail: sbd983@yahoo.com

Received: 30.01.2017, accepted: 16.07.2017. 

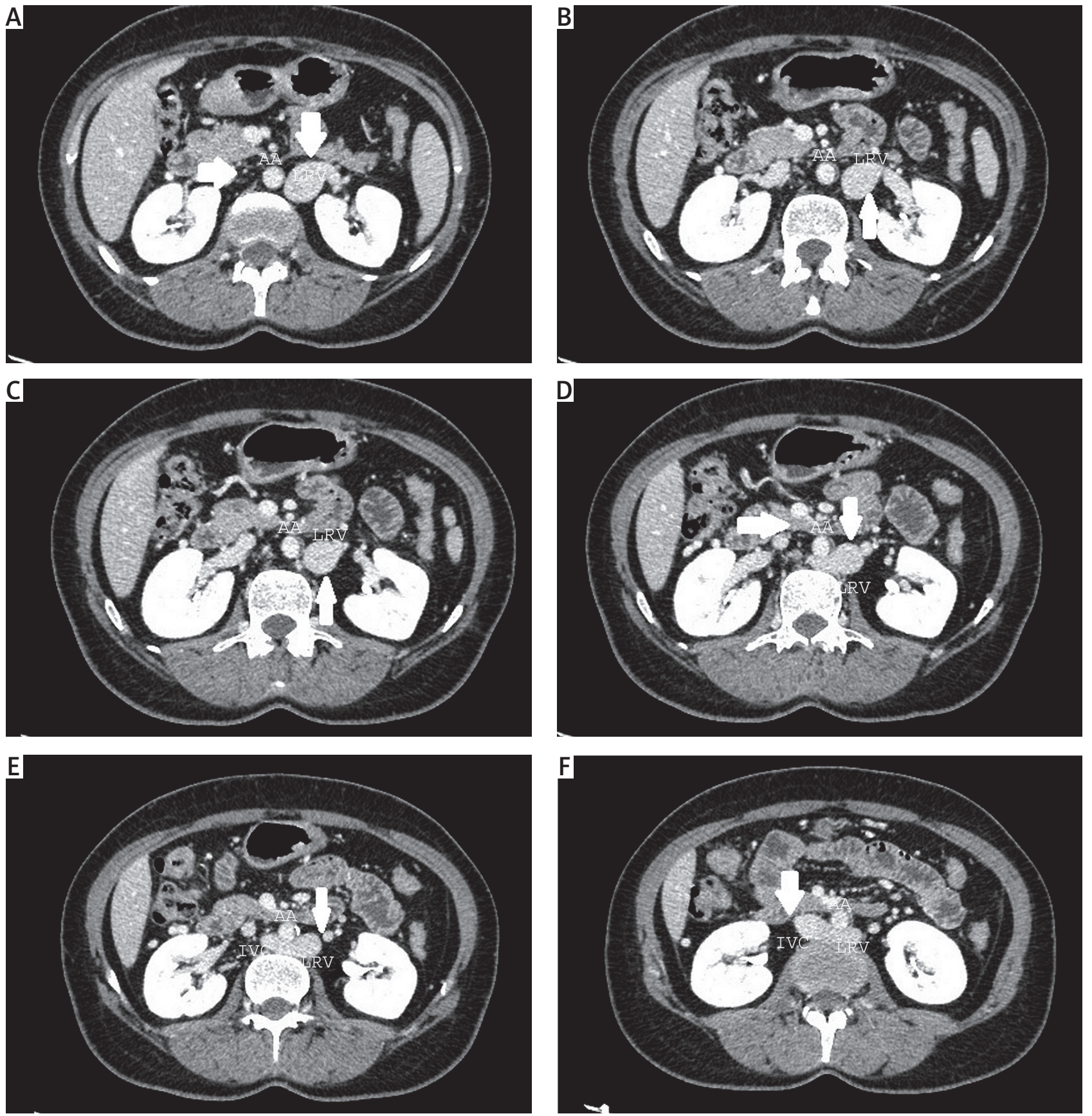

Fig. 1. Computed tomography image of congenital agenesis of inferior vena cava (IVC) associated with retro-aortic nutcracker syndrome $A A$ - abdominal aorta, LRV - left renal vein

stage of chronic venous insufficiency and acute thrombosis of the iliofemoral vein in case of collateral collapse.

\section{Disclosure}

Authors report no conflict of interest.

\section{References}

1. Gil RJ, Pérez AM, Arias JB, Pascual FB, Romero ES. Agenesis of the inferior vena cava associated with lower extremities and pelvic venous thrombosis. J Vasc Surg 2006; 44: 1114-1116.
2. Luo X, Qian G, Xiao H, Zhao C, Zhou X. Posterior nutcracker syndrome associated with interrupted left inferior vena cava with azygos continuation and retroaortic right renal vein. Korean J Radiol 2012; 13: 345-349.

3. Applegate KE, Goske MJ, Pierce G, Murphy D. Situs revisited: imaging of the heterotaxy syndrome. Radiographics 1999; 19: 837-854.

4. Kwaśniak E, Juściński J, Haponiuk I, Chojnicki M, Jaworski R, Steffek M, Zabolska I, Mozol K, Zieliński J, Gierat-Haponiuk K. Heterotaxy syndrome in a patient with congenital thoracic duct anomaly and pericardial defect - a case report. Kardiochir Torakochir Pol 2011; 8: 209-212.

5. Deser SB, Onem K, Demirag MK, Buyukalpelli R. Surgical treatment of posterior nutcracker syndrome with hyperaldesteronism. Interact Cardiovasc Thorac Surg 2016; 22: 682-684. 